\title{
Relationship between atmospheric circulation and stable isotope composition of Belgrade daily precipitation
}

\author{
Nada Miljević, Ana Pešić \\ Jaroslav Cerni Institute \\ for Development of Water Resources, Belgrade \\ Zoran Gršić \\ Nuclear Facilities of Serbia, Belgrade
}

\author{
Dušan Golobočanin \\ Vinca Institute for Nuclear Sciences, Belgrade
}

\author{
Miroslava Unkašević, Ivana Tošić \\ Institute of Meteorology, Faculty of Physics, \\ University of Belgrade, Belgrade
}

\begin{abstract}
Daily precipitation was collected in the period from May to December 2010, along with the corresponding meteorological data (air temperature, humidity, amount of precipitation) in the Vinca Institute of Nuclear Sciences $\left(44^{\circ} 45^{\prime} 33^{\prime \prime}\right.$ N, $20^{\circ} 35^{\prime} 57^{\prime \prime}$ E), Belgrade, Serbia. On the basis of backward trajectory analysis, three dominant trajectory categories are determined: southwestern Europe (SW) northeastern Europe (NE), and northwestern Europe (NW), which were associated with $49(71 \%)$ of the events. The highest daily $\delta^{18} \mathrm{O}$ and $\delta^{2} \mathrm{H}$ values were measured on 9 December $(-1.3 \%$ and $-8.7 \%$, respectively), whereas the lowest values were measured on 28 December $(-143.2 \%$ and $-19.3 \%$, respectively). Circulation back trajectories, synoptic-scale surface and middle-tropospheric weather maps, and $\delta^{2} \mathrm{H}$ and $\delta^{18} \mathrm{O}$ values for 69 precipitation samples, were examined to determine the origin and direction of the air masses for each event.
\end{abstract}

Keywords: daily precipitation, Belgrade, stable isotope content

\section{Introduction}

Factors that control stable isotopic compositions $\left(\delta^{2} \mathrm{H}\right.$ and $\left.\delta^{18} \mathrm{O}\right)$ of precipitation involve fractionation processes associated with the evaporation and condensation history of the precipitating water vapor. These factors include the temperature, the amount of precipitation, the isotope value of the water vapor

Addresses: N. Miljević, A. Pešić: Jaroslava Cernog 80, 11226 Belgrade, Serbia, e-mail: emiljevi@vinca.rs

D. Golobočanin: POB 522, 11001 Belgrade, Serbia, e-mail: golddus@gmail.com Z. Gršić: Mike Petrovica Alasa 12-14, 11351 Belgrade, Serbia, e-mail: grsa@vinca.rs M. Unkašević, I. Tošić: POB 368, 11000 Belgrade, Serbia, e-mails: miroslava@ff.bg.ac.rs, itosic@ff.bg.ac.rs

Received: May 14, 2011; accepted: May 26, 2011 
source, and the degree the amount of vapor decreased during its travel over land. Therefore, $\delta^{2} \mathrm{H}$ and $\delta^{18} \mathrm{O}$ values of precipitation are strongly influenced by the trajectory history of water vapor and could be used as a tool for the reconstruction of atmospheric circulation (Burnett et al. 2004). Our goal was to collect the sample representing the precipitation that had fallen over the previous 24 hours in order to understand the relationship between atmospheric circulation and stable isotope content of individual precipitation events in Belgrade area.

\section{Sampling and analytical techniques}

Daily precipitation was collected by a funnel attached to a $500 \mathrm{ml}$ bottle mounted on a $1 \mathrm{~m}$ post (surface $200 \mathrm{~cm}^{2}$ ) in an open setting during the period from May to December 2010 in the Vinca Institute of Nuclear Sciences $\left(44^{\circ} 45^{\prime} 33^{\prime \prime}\right.$ N, 203'ㄱ" E), Belgrade, Serbia. The corresponding meteorological data: air temperature (sensor DTA 32A), humidity (Vaisala Humidity probe HMP 45D), and amount of precipitation (rain and snow gauge, Helman type) were recorded using an automatic AMES weather station installed $2 \mathrm{~m}$ above the ground. However, during weekends and holidays precipitation was collected as a composite sample. Water samples for stable isotopes were analyzed using laser absorption spectroscopy (LGR DLT-100). Stable isotopes are measured relative to VSMOW using internal standards calibrated with international standards. The precision of measurements was usually better than $\pm 1 \%$ or $\delta^{2} \mathrm{H}$ and $\pm 0.2 \%$ for $\delta^{18} \mathrm{O}$.

Two-day backward trajectories were computed for a time period of 48 hours prior to the time each sample was collected (at a start time of 07:00 local time), using the Hybrid Single-Particle Lagrangian Integrated Trajectory (HYSPLIT) model (Draxler and Rolph 2003). Trajectory data were coupled with a qualitative assessment of weather conditions for each precipitation event using synopticscale surface and middle-tropospheric weather maps.

\section{Results and Discussion}

Air mass trajectories were classified into five trajectory categories (69 cases) by the direction of their approach to Belgrade: northern Europe $(\mathrm{N})$, northeastern Europe (NE), southeastern Europe (SE), southwestern Europe (SW) and northwestern Europe (NW). The most frequent precipitations are associated with the SW category $(36.2 \%)$, followed by NE $(21.7 \%)$ and NW $(20.3 \%)$.

The isotopic data show large variation. The highest daily $\delta^{18} \mathrm{O}$ and $\delta^{2} \mathrm{H}$ values were measured on 9 December $(-1.3 \%$ and $-8.7 \%$, respectively), whereas the lowest values were measured on 28 December $(-19.3 \%$ and $-143.2 \%$, respectively). We have found a relationship between the $\delta^{18} \mathrm{O}$ values and the mean effective surface air temperature during the precipitation event $\left(\delta^{18} \mathrm{O}=\right.$ $\left.0.37( \pm 0.05) \mathrm{T}-12.6( \pm 0.7), \mathrm{n}=69, \mathrm{r}^{2}=0.47\right)$. About $50 \%$ of the precipitation $\delta^{18} \mathrm{O}$ 
variability cannot be explained by surface air temperature alone. The most extreme average residual $\delta^{18} \mathrm{O}$ values were associated with the NW $(11.3 \%$ ) and SW sector $(+6.6 \%$ o events, indicating that these events yield precipitation that is more negative and positive, respectively, than would be expected through daily surface temperature alone.

A scatter plot showing the $\delta^{18} \mathrm{O}$ and $\delta^{2} \mathrm{H}$ values for each sample coded by weather type, together with the long-term (1992 and 2005) local meteoric water line (LMWL) for Belgrade $\left(\delta^{2} \mathrm{H}=7.8( \pm 0.2) \delta^{18} \mathrm{O}+7.3( \pm 1.6)\left(\mathrm{r}^{2}=0.98, \mathrm{n}=60\right)\right.$ (Golobočanin et al. 2007) is shown in Fig. 1. The $\delta^{18} \mathrm{O}$ of NW precipitation, influenced by the Atlantic air masses, is the most negative, with an average of $10.4 \%$ o $(\sigma=4.0 \%, \mathrm{n}=14)$. NE events, originating from the interior of the European continent, and SW ones influenced by the Mediterranean air masses, had similar higher values, with averages of $-7.5 \%$ o $(\sigma=4.3 \%$, $\mathrm{n}=14)$ and $-6.2 \%$ o $(\sigma=3.8 \%, \mathrm{n}=21)$, respectively. The highest $\delta^{18} \mathrm{O}$ values are associated with the warm $\mathrm{S}$ sector events, with $-4.5 \%$ o $(\sigma=0.7 \% \circ, \mathrm{n}=2)$, but they belong to the less frequent types. The mean $\delta^{18} \mathrm{O}$ value of the "other" weather type category, which captures a wide range of less frequent types, such as $E$ with $-10.1 \%$ o $(\sigma=2.4 \%$, $\mathrm{n}=3)$ and SE with $-9.0 \%(\sigma=5.6 \%, \mathrm{n}=4)$, falls in the range characteristic for the period of the year when the dominant winter air masses would be of cold continental origin. We have found that a strong relationship exists between the isotopic content of precipitation for a given event and the back trajectory of the air mass. In general, the $\delta^{18} \mathrm{O}$ value decreases systematically as the precipitation weather category changes from SW to NW.

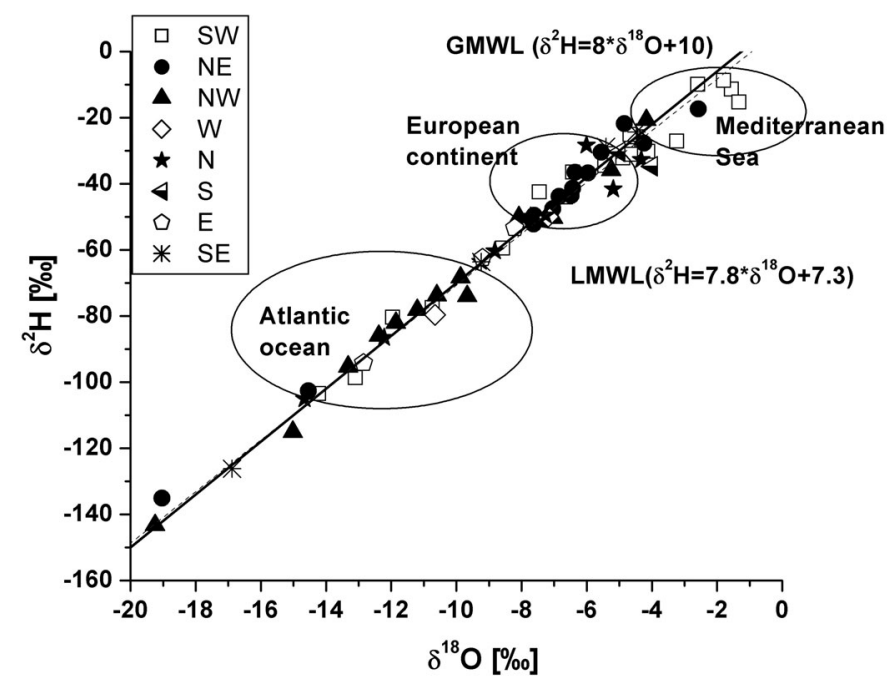

Fig. 1

Correlation between $\delta^{18} \mathrm{O}$ and $\delta^{2} \mathrm{H}$ for daily precipitation samples (May-December 2010) coded by circulation type. The local meteoric water line is based on a linear regression through the 1992-2005 observations (Golobočanin et al. 2007) 
Deuterium excess ( $d$-excess), defined as $d=\delta^{2} \mathrm{H}-8 \delta^{18} \mathrm{O}$, can be related to the meteorological conditions in the oceanic source region from where the water vapor is obtained. However, vapor evaporated in continental basins can modify the original 'oceanic' signal and $d$-excess is strongly affected by local humidity as well as wind speed and sea surface temperature during primary evaporation (Merlivat and Jouzel 1979). The daily d-excess values for the Belgrade precipitation fell in the range of $-4.7 \%$ o to $+19.8 \%$, with a mean value of $8.4 \pm$ $3.7 \%$ and $10.1 \pm 5.3 \%$ o for the period of May-August and September-December, respectively (Fig. 2). Low values of $d$-excess ( $0 \%$ ) recorded in some samples, mostly in the warmer period (May 14, June 14, November 11), can be explained by the secondary evaporation processes between cloud base and ground that occur under conditions of a very low amount of precipitation $(<3 \mathrm{~mm})$ at relatively high temperature $\left(>16^{\circ} \mathrm{C}\right)$ and low relative humidity $(<59 \%)$.

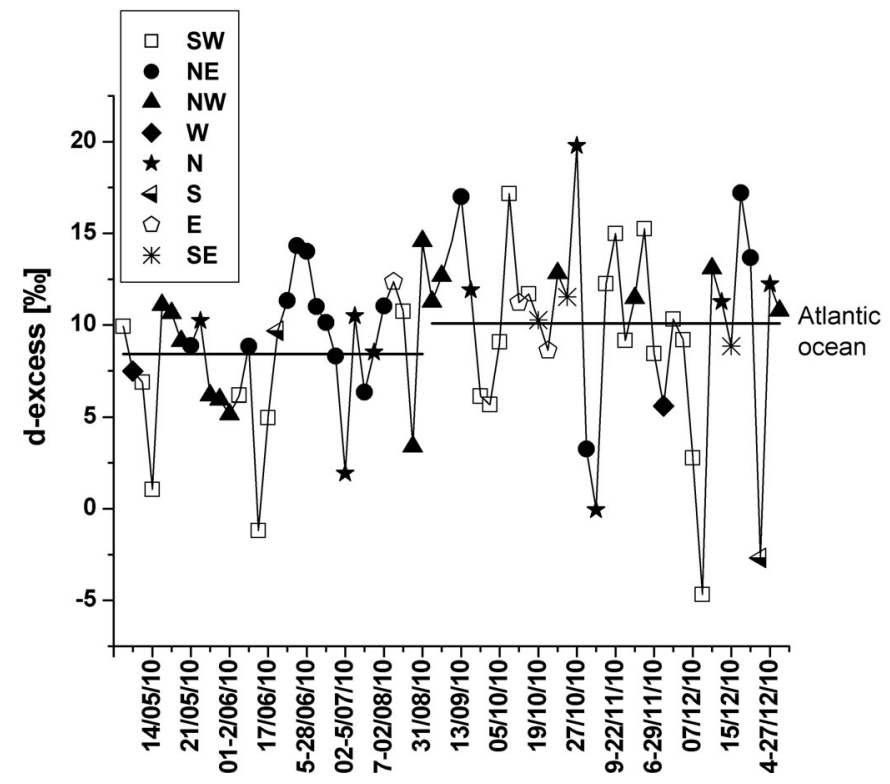

Fig. 2

Time-series variations of $\mathrm{d}$ excess in the Belgrade area (May-December 2010) coded by circulation type

\section{References}

Burnett, A.W., H.T. Mullins, W.P. Patterson 2004: Relationship between atmospheric circulation and winter precipitation $\delta^{18} \mathrm{O}$ in central New York State. - Geophys Res Let, 31, L22209, doi: 10.1029/200GL021089.

Draxler, R.R., G.D. Rolph 2003: HYSPLIT (HYbrid Single-Particle Lagrangian Integrated Trajectory) Model access via NOAA ARL READY Website (http://www.arl.noaa.gov/ready/hysplit4.html). NOAA Air Resources Laboratory, Silver Spring, MD.

Golobočanin, D., N. Ogrinc, A Bondžić, N. Miljević 2007: Isotopic characteristics of meteoric waters in the Belgrade region. - Isot. Environ. Health S, 43, pp. 355-367.

Merlivat, M., J. Jouzel 1979: Global climatic interpretation of the deuterium-oxygen-18 relationship for precipitation. - J. Geophys. Res., 84, pp. 5029-5033. 